This item was submitted to Loughborough's Research Repository by the author.

Items in Figshare are protected by copyright, with all rights reserved, unless otherwise indicated.

\title{
How does marriage affect physical and psychological health? A survey of the longitudinal evidence
}

PLEASE CITE THE PUBLISHED VERSION

http://www.iza.org/en/webcontent/publications/papers

\section{PUBLISHER}

Institute for the Study of Labor (IZA)

VERSION

VoR (Version of Record)

\section{PUBLISHER STATEMENT}

This work is made available according to the conditions of the Creative Commons Attribution-NonCommercialNoDerivatives 4.0 International (CC BY-NC-ND 4.0) licence. Full details of this licence are available at: https://creativecommons.org/licenses/by-nc-nd/4.0/

\section{LICENCE}

CC BY-NC-ND 4.0

\section{REPOSITORY RECORD}

Wilson, Chris M., and Andrew J. Oswald. 2019. "How Does Marriage Affect Physical and Psychological Health? A Survey of the Longitudinal Evidence”. figshare. https://hdl.handle.net/2134/16485. 
IZADP No. 1619

How Does Marriage Affect Physical and Psychological Health? A Survey of the Longitudinal Evidence

Chris M. Wilson

Andrew J. Oswald

May 2005 


\title{
How Does Marriage Affect Physical and Psychological Health? A Survey of the Longitudinal Evidence
}

\author{
Chris M. Wilson \\ University of East Anglia \\ Andrew J. Oswald \\ University of Warwick, Harvard University \\ and IZA Bonn
}

Discussion Paper No. 1619

May 2005

IZA

P.O. Box 7240

53072 Bonn

Germany

Phone: +49-228-3894-0

Fax: +49-228-3894-180

Email: iza@iza.org

Any opinions expressed here are those of the author(s) and not those of the institute. Research disseminated by IZA may include views on policy, but the institute itself takes no institutional policy positions.

The Institute for the Study of Labor (IZA) in Bonn is a local and virtual international research center and a place of communication between science, politics and business. IZA is an independent nonprofit company supported by Deutsche Post World Net. The center is associated with the University of Bonn and offers a stimulating research environment through its research networks, research support, and visitors and doctoral programs. IZA engages in (i) original and internationally competitive research in all fields of labor economics, (ii) development of policy concepts, and (iii) dissemination of research results and concepts to the interested public.

IZA Discussion Papers often represent preliminary work and are circulated to encourage discussion. Citation of such a paper should account for its provisional character. A revised version may be available directly from the author. 
IZA Discussion Paper No. 1619

May 2005

\section{ABSTRACT}

\section{How Does Marriage Affect Physical and Psychological Health? A Survey of the Longitudinal Evidence*}

This paper examines an accumulating modern literature on the health benefits of relationships like marriage. Although much remains to be understood about the physiological channels, we draw the judgment, after looking across many journals and disciplines, that there is persuasive longitudinal evidence for such effects. The size of the health gain from marriage is remarkable. It may be as large as the benefit from giving up smoking.

JEL Classification: I0, I12

Keywords: mortality, health, marriage, happiness, longitudinal

Corresponding author:

Andrew J. Oswald

University of Warwick

Coventry, CV4 7AL

United Kingdom

Email: Andrew.Oswald@warwick.ac.uk

\footnotetext{
* Work on this paper was done while the second author was a Wertheim Fellow at Harvard University.
} 


\section{$\underline{\text { Introduction }}$}

Economists know that human beings reap financial benefits from marriage. Even after controlling for other factors, married individuals earn much more than single people (e.g. Chun and Lee (2001), Daniel (1995), Loh (1996), Reed and Harford (1989)). There are gains, too, from economies of scale within the family (Becker 1981).

Yet economists are less aware of an emerging body of research that finds wider benefits from marriage -one that suggests the mind and the body are intertwined in ways not fully understood. Sociologists, psychologists and epidemiologists have recently documented evidence of married people’s better physical health, longevity, psychological health, and reported happiness. Married individuals fare better in these terms than the never married, who in turn do better than the divorced, separated and widowed. Often the coefficients in such research imply strikingly large consequences from relationships. For example, using pooled cross-sections for the US and the UK, Blanchflower and Oswald (2004a) estimate the size of the marriage effect upon mental well-being to be equal to that from an extra $\$ 100,000$ dollars a year. Formal marriage itself seems to matter. In the few studies that compare married and non-married cohabiters, the results typically show an extra beneficial effect from being married. A common conclusion also asserts that these benefits are larger for men than for women; pioneering work here was done by Gove et al (1983). Finally, some argue that the benefits to happiness may be declining over time, relative to the nonmarried (Lee et al 1991, Glenn and Weaver 1988).

This paper tries to assess these ideas. It is not a comprehensive survey -- the literature is already too large for that -- but it attempts, by looking across diverse literatures, to draw general messages that seem of interest to economists and other social scientists. Past reviews include Ross et al (1990), Burman and Margolin (1992) and Kiecolt-Glaser (2001) on physiological evidence, Coombs (1991) on wellbeing, and Waite (1995) on evidence of health, financial and other benefits. Waite and Lehrer (2003) compare the benefits from marriage with the benefits associated with being religious.

In contrast to previous reviews, we concentrate on longitudinal evidence. The reason is that to economists (and many other kinds of investigators) this type of evidence is more persuasive than that from crosssections. In cross-sectional patterns, causality is difficult to unearth. Although panel data do not always provide a solution, the ability to look at events through time is an advantage. First, panel data offer before-and-after evidence. Second, panel data make it possible to difference out -- in the econometric sense -- the underlying characteristics of the individuals being studied. 
We start in section I by looking at the possible mechanisms at work behind a correlation between health (mental or physical) and marriage. The section discusses methodological problems in this area, and how researchers have tried to resolve them. Section II reviews the effects of marriage on mental health. In these research studies, the benefits of marriage are commonly measured by studying the effect of matrimony on depression and alcohol abuse. Section III examines mortality. It shows that, after controlling for other factors, married people are far less likely to die in any given period than the nonmarried. Section IV reviews the correlations between marriage and physical health. Finally, section V discusses tests of the channels from marriage to wellbeing.

\section{$\underline{\text { Section I: Methodological Issues }}$}

How are well-being and marital status interconnected? First, marriage may itself lead to improved physical and mental health. This has been called the protective effect of marriage. Alternatively, simple correlations could be interpreted as telling us merely that certain types of people can persuade a partner to marry them. This is the so-called selection effect.

According to evolutionary principles, it would be no surprise if physically and mentally healthier individuals are more attractive to mates, and thus more likely to show up in data sets as married (and to stay married). Hence better health could be a cause of marriage. If panels are not sufficiently long -stretching back before the date of marriage -- it may be impossible to correct fully for selection. In this research area, Lillard and Panis (1996) and Brockmann and Klein (2004) contain valuable discussions of how to control for selection. Cohen (2004) considers the possible channels from marriage to health; Ren (1997) argues that marital quality and marital history should be held constant in testing; the intriguing idea of using twins data is explored in Kohler et al (2004).

Selection effects need not work in a simple way. Joung et al (1998) explain with reference to Collins and Coltrane (1992) that, if assortative mating occurs, unhealthy people with unhealthy partners are more likely to be widowed. This could lead to a spurious relationship suggesting that widowhood causes ill health. Alternatively, Lillard and Panis (1996) suggest that if marriage does give beneficial effects, then physically and mentally unhealthy individuals will face the greatest incentive to marry, giving an 'adverse' selection effect. As we shall see, the existence of adverse selection effects rather than the standard selection effect is supported by the evidence, but only for males. The mechanisms leading to possible benefits from marriage have been explored. In section V, we look more closely at the research 
evidence. Here we review some suggested theoretical explanations. Further discussion is available in Ross et al (1990) and Wyke and Ford (1992).

On the grounds that two can live almost as cheaply as one, marriage may work simply because it provides higher real income per partner. Poorer standards of living are correlated with mental health problems (Ross et al 1990). Ross (1995) also shows that the married have the lowest incidence of economic hardship, while Smock et al (1999), who study 'switchers', find clear financial benefits for married women. Second, marriage is a source of emotional and instrumental support. Emotional help seems to reduce the incidence of depression and mental illness (Ross et al 1990), and may provide an important buffer against stress (Kessler and Essex 1982, Berkman 1988). Marriage can also enhance feelings of attachment and belonging, which are thought to affect mental health (House et al 1988), while releasing people from any possible social stigma associated with being unmarried. Single people are more likely to live alone, which is known to be associated with depression (Ross et al 1990). Emotional help can, nevertheless, come from sources outside marriage. Social networks thus may be important, especially for the unmarried. A common conjecture about why the benefits from marriage are larger for males than females is that women have more developed social networks outside marriage, and these already give valuable support (Schumaker and Hill 1991). A third mechanism is the so-called guardian role. Married individuals act differently from single people. They tend to engage less in risky activities and more in healthy ones - perhaps for the sake of their partner (Umberson 1987, Ross et al 1990, Power et al 1999). For example, married people smoke and drink less. Moreover, partners probably unconsciously monitor each other for early symptoms of illness.

Early cross-sectional evidence could not distinguish between selection and protection effects. One line of attack since then has been to try econometrically to estimate the size of the selection effect. In theory, this can be done by using pre-marital characteristics to predict later marital status (e.g. Joung et al 1998, Masterkaasa 1992), and then, after subtracting the selection effect, viewing any correlation between health and marriage that remains as the true size of the protection from being married. Longitudinal data should allow this.

In calculating the effects on mental health, for instance, the following approach is common. Measures are obtained of mental health at time T1, before marriage, and at time T2, when marital status has changed for some of the individuals in the sample. OLS regressions are then performed to explain mental health at time T2, while including both a set of explanatory variables and the mental health measure at time T1. The inclusion of mental health at T1 acts as a simple control for pre-marital psychological well-being. In 
principle, any relationship then found between mental health and marriage should not be a spurious selection effect. Most evidence of this sort suggests that a protective effect exists.

These regressions must be specified, however, with all the potential explanatory variables that affect mental health at T2. Often-included variables are measures of social integration outside marriage, employment status, income and frequency of financial problems, age, gender, race, and parental status. Unfortunately, only some of these variables are typically included in any one study, and the influence of physical health is often neglected. This is a potentially serious omission, because health is an important determinant of happiness (Stack and Eshleman 1998). If health is positively correlated with the likelihood of marriage, that will produce an upward bias on the marriage coefficient, and lead to an overstatement of the benefits of marriage.

\section{Section II: Mental Health Benefits from Marriage}

We start with the mind.

Gove et al (1983) is an early cross-section study. This uses US data, and finds marriage to be the best predictor of happiness after controls are added for education, age, gender and race. The authors take steps to try to counter the selection problem by including a "bad childhood experiences" variable, which they think will predict pre-marital wellbeing. The paper finds the beneficial effects of marriage to be larger for men than for women. Also, using the married sample only, marriage quality is the single best predictor of wellbeing.

More recent cross-section evidence, by Stack and Eshleman (1998), considers 17 developed nations. Controls are included for gender, age, health, financial situation, children, education, religion, national marriage and divorce rates, GDP/capita, and income distribution measures. This research finds financial situation to be the best predictor of happiness -- followed by health, followed by marital status. The married turn out to be happier than those who cohabit, who are themselves happier than single individuals, ceteris paribus. In regressions on each nation separately, for sixteen of seventeen nations the marriage coefficient is positive in a wellbeing equation. The existence of this cross-section pattern is now

quite firmly established. Similar patterns are reported, for instance, for European countries in modern data in Di Tella, MacCulloch and Oswald (2003). 
Could this be an illusion within the data? Johnson and Wu (2002) argue that there are three potential reasons why married people might incorrectly appear to have better psychological health. First, married people were actually happier before they married; this is the selection effect. Second, in a cross-section of individuals, some of the married people have only recently been married, and this initially makes them happy, but does not do so in the long-run, because they adapt back to 'baseline'. Third, marriage and divorce are correlated with important kinds of social roles and networks, and it may be these that add to or reduce well-being; this is a kind of omitted-variable argument.

Several papers have used longitudinal data to estimate the benefits of marriage for mental health, and to adjust for the selection problem. Horwitz et al (1996) find significant benefits from marriage -- both reductions in depression for married women, and reductions in alcohol abuse for married men. Simon and Marcussen (1999) demonstrate that marriage cuts the probability of depression. In Horwitz et al (1996), psychological health gains are measured by using a standard 10-item depression index, and alcohol abuse by a similar index measuring the frequency of various drinking problems. This data set is the Rutgers Health and Human Development Project in the US: it follows approximately 1400 subjects, aged 12,15 and 18 years old, for seven years from sixteen of the twenty-one New Jersey counties. The subjects are tested at four points across the seven years. Seven years may be too short a follow-up period to be ideal. A response rate of less than $50 \%$ is obtained. Only the respondents who never married over the whole period (482), and the respondents who were consistently married between the $3^{\text {rd }}$ and $4^{\text {th }}$ period (347), are used. Rather interestingly, the research finds that depression and alcohol abuse fall over the seven years for all groups, but it declines most steeply among the married sample. Independent variables include age, gender, individual income, and a 22-item index of social integration; the last of these is used to account for the apparently anti-depressive effects of having extensive networks of friends.

The data reveal a large and significant marital effect upon depression by the $4^{\text {th }}$ period. Higher incomes and greater levels of social support also significantly reduce the probability of depression, while age and gender have no statistically significant effect. Even after the controls are added, being married produces a significantly reduced score in the depression index $(\mathrm{p}<0.05)$. Next, alcohol-abuse measures are used. Again, initial scores on the index give a significant effect, though not so large. Men have much higher levels of problems with drink than women; age is associated with reduced drinking problems; neither income nor social support has a statistically significant effect. Marriage produces a beneficial effect above these controls, which is large and significant at better than the $1 \%$ level. The authors argue that these are consequences that stem from marriage independently of any selection effect. 
As an extension, the Horwitz et al data are split into male and female sub-samples. For depression, being married has a beneficial effect among men. No significant difference emerges between married and single women. The results are reversed when using alcohol abuse measures. Married women report a significant improvement.

To investigate the exact nature of the gain, the married sample is scrutinized separately. The level of depression / alcohol abuse is regressed on the control variables, and some new variables, including a marital quality 20-item scale, to incorporate differences in the nature of marital relationships, the presence of children, and marital duration. Aside from initial characteristics, the marriage quality index is the strongest explanatory variable, with a large beneficial effect, this time at a significance level of less than $0.1 \%$. Marriage quality itself is important in reducing mental health problems.

What people think of marriage also turns out to matter. Simon and Marcussen (1999) add to the literature by showing that beliefs about marriage are correlated with the mental-wellbeing benefits gained from being married. The authors demonstrate that individuals who value the permanence and importance of marriage have a larger reduction in depression, and suffer more from marriage dissolution. Panel data from the US National Survey of Families and Households (1987-88 and 1992-1994) are studied. Knowing individuals' beliefs and initial status at 1987/8 (T1) allows an examination of the effect of beliefs on marital status. In total, 10,005 adults are interviewed, with $74 \%$ and $82 \%$ response rates. Attrition is a problem, especially among those unmarried at T1, so the results here may have to be evaluated with care.

A standard depression scale is employed by the authors -- based on responses to questions on the number of days they felt lonely, not having an appetite, etc. Two dummies are constructed to show marital gain and loss in the time intervals. Marital beliefs are measured by questions about the perceived importance and desirability of marriage. Control variables include age, years of education, gender, race, household income and parental status. Noticeably, measures of social integration and health are missing.

Large effects are found. Depression at T1 is significantly higher among the individuals about to experience a marital loss. Selection effects are not supported, however, because depression at T1 is not significantly different for those about to experience a marital gain, or for the never married. Those who feel strongly about marriage experience the largest gains from marrying.

The paper then investigates the effect of changes in marital status upon depression. It uses T1 depression measures to control for selection effects. Older, more educated, higher income, employed individuals are 
significantly less depressed. Parenthood has no significant effect, which is consistent with results reviewed in McLananhan and Adams (1987) and Ross et al (1990). Initial depression is a strong predictor of depression at T2, as would be expected. Even with other factors held constant, marital break-up has a large depressive effect $(\mathrm{p}<0.001)$, and getting married gives a beneficial effect $(\mathrm{p}<0.001)$. With interaction terms, it is shown that women have more depression after a marital split. This perhaps runs counter to the view that men benefit more from marriage. When the belief variables are added (interacted with marital gain/loss) the expected results are found. In terms of the probability of depression, those who believe in the importance of marriage gain more after marriage and lose more after divorce. Empirical support for the protective effect is found, with less evidence of selection.

Barrett (2000) investigates marital history. The paper uses the Piedmont Health Survey, which provides full marital and mental histories for a group of adults from North Carolina. A premarital psychological health measure is available in the data set -- with symptoms of disorders in the past 12 months, categorised into depression, anxiety and substance abuse. Variables are created to compare the various marital history groups. The author's results confirm the existence of big psychological gains from marriage. An intriguing finding is that second and third marriages seem to produce smaller improvements in mental well-being.

Striking results on the power of marriage are provided by Marks and Lambert (1998), who use a twowave panel from the US National Survey of Families and Households (for the periods (1987-88) and(1992-93)). The authors analyse the effects of marital history on well-being and have a particular interest in whether effects differ by age and gender. Marital history is captured by a comprehensive set of ten marital states. Well-being is measured with a large set of measures that range from depression, happiness, and self esteem, to irritability and purpose in life. An individual's well-being in the later period is regressed on marital history, controlling for the individuals' previous well-being values in 1987-88, and for other personal characteristics. Compared to those continually married, the continually separated/divorced show significantly lower levels of mental health. Similarly, the widowed have significantly increased chances of depression; the continually single are less happy and more depressed, but do exhibit higher autonomy and personal growth. Transition to marriage from being never-married strongly increases almost all measures of psychological wellbeing, and remarriage also works but offers reduced benefits. A transition from marriage to separation or widowhood increases depression and unhappiness. In contrast to some evidence, this effect is most pronounced for women. Notably, adverse effects seem to be reliably tempered by middle age. 
With the same data, Kim and McKenry (2002) address similar questions but look at cohabitation. The authors are thorough. They combine extensive controls for the quality of the relationship with survey responses on fairness, disagreements, satisfaction and conflict (in addition to the usual other characteristics, and initial well-being). As expected, the quality variables help to explain individuals' well-being, but the pure marital effect is still significant in the data. Intriguingly, unlike marriage, cohabiting here produces few benefits. This study also finds against strong selection effects. Initial depression has negligible consequences for observed marital transitions. This evidence reinforces the measured protection effects from marital transitions, but leaves the comparisons between continual marital states still open to the selection explanation.

These NSFH data are also used in Simon (2002). Compared to the continuously married, the author discovers that a loss from separation or divorce is associated with an increase in depression and alcohol abuse, and these effects are larger for women than men (as also observed by Marks and Lambert (1998)). Yet there are no statistically significant effects from widowhood. Marital gains led to benefits in both wellbeing measures -- equally for men and women -- but these only seem to exist for the first marriage.

There are a number of differences between marriages and non-married partnerships. Obviously the level of commitment may be different, but more subtle differences are also present. Cohabiters seem more likely to have lower quality relationships (Brown and Booth 1996) and unstable ones (Brown 2000), and more often have lower socio-economic status (Rindfuss and VandenHeuvel 1990). The unmarried livingtogether group is particularly of interest because in Western society its size is growing. Presumably many cohabiters are 'testing' their relationship to assess its long-term suitability. Within the US, more than half of marriages are preceded by cohabitation (Bumpass and Sweet 1989). In 1970, half a million cohabiters existed; today, the figure exceeds four million.

Looking across the literature, is cohabitation as good as having the band of gold itself? It seems not. Two papers find less depression among married people than among cohabiters. Brown (2000) argues that this is likely to result from the extra stability of a marriage. Horwitz and White (1998) establish that single people are similar to cohabiters in having more depression than the married. Cohabiters are shown to be the group with the highest alcohol abuse. Brown (2000) investigates depression with panel data from the US National Survey of Families and Households (1987-88 and 1992-1994). This includes 646 cohabiters and 3086 married respondents. The data set allows the entire sample to be single at the first point of measurement (to control for initial characteristics). To assess depression, Brown draws upon the same scale as Simon and Marcussen (1999), and shows that the average cohabiter score is 16.3, against an 
average married person's score of 13.0. Two variables for socio-economic status are used -- years of education and total couple’s earnings. Cohabiters' average years of education are 12.4, compared to 13.2 for the married (significantly different at $<1 \%$ ). The couples’ earnings, by type, are also significantly different. Cohabiters average \$30,000 per annum, and the married $\$ 37,000$. Dummy variables are included for the presence of biological and step children. In case of differences in relative power, the respondents are asked their individual earnings and housework hours per week. Relative measures of these are used. Interestingly, respondents provide information, on a scale of 1-5, on their perception of the stability of the relationship. Cohabiters record significantly $(<1 \%)$ more instability than the married: a mean score of 1.91 compared to 1.45 for the married. Other controls for depression include age, gender, race, prior union experience, and current union duration. Social integration and health measures are missing.

At first, Brown carries out cross-section regressions. Without including partnership-union characteristics, cohabiters are significantly more depressed. Depression scores are 2.5 points higher at a significance level of less than $0.1 \%$. However, the addition of union characteristics apparently explains this; the cohabitation dummy loses its significance. The instability effect is large and significant $(<0.1 \%)$. Couple's earnings are a negative predictor of depression. The presence of children has no robust effect, as in the research of Ross et al (1990) and McLanahan and Adams (1987). As usual, age and education act to reduce the risk of depression, as does being male. The duration of the cohabiting union has a bad effect upon the depression probability, statistically significant at $<5 \%$. This is due to the high depression scores of long-duration cohabiters and long-duration childless couples.

To account for selection into the two groups, the longitudinal nature of the data is then exploited. At the first point in time, pre-union depression scores are not significantly different between the two groups. However, the scores in the second period are striking (see their Table 1, p.246). Marriage is associated with an enormous improvement in later mental health.

Although marital status itself seems to be causing the change, this is checked more fully with a Heckmancorrection estimator. An underlying equation for the decision to marry is estimated, and this is used to model depression in Period 2, while including the explanatory variables and Period-1 depression scores. Cohabitation emerges with a 2.8-point effect upon depression $(p<0.05)$. The selection variable from the first stage of the Heckman method does not have a coefficient that is statistically significantly different from zero, which suggests a minor role for selection effects between marriage and cohabitation. As would 
be expected, Period-1 depression is independently associated with Period-2 depression. When union characteristics are added, the results roughly mimic the cross-sectional findings.

Horwitz and White (1998) employ the same data as Horwitz et al (1996). Cohabiting men have the highest levels of alcohol problems. A broad conclusion, then, is that cohabiting provides no benefits in terms of depression or alcohol abuse. This matters because it seems to indicate that the benefits from marriage do not originate solely from living with someone.

Another way to tackle the selection problem has been to model the choice mechanism. One interesting paper is Masterkaasa (1992). Here the mental wellbeing of a sample of 9000 unmarried individuals in Norway is assessed. This sample is then re-interviewed 2-4 years later. Causality can be studied, arguably, by assessing whether the initial wellbeing assessments predict marital status at the follow up stage. It might be guessed that the happier, more satisfied individuals are the ones more likely later to be married. To test this, a Cox regression is used to estimate the duration before marriage; a probability density function is estimated with maximum likelihood methods, in terms of time and explanatory variables. The duration density function is transformed into a hazard function, representing the probability of transition, which is straightforward to interpret. The effects of the explanatory variables on the probability of transition can then be calculated.

In a different tradition altogether, Kohler et al (2004) is an outstanding paper. These authors study the relationship between subjective well-being and partner and fertility status. The novelty and attraction of this study is that it uses variations within pairs of twins in order to control for any unobservable genetic or childhood factors that may influence well-being and status. This can provide a way to control for selection effects and can ensure a more direct test for causality from marital status to well-being. To fully control for the selection effect, individual panel data sets ideally need measurements on individuals' wellbeing before they get married, which is usually hard to obtain, whereas variation in twins' outcomes is a different way to proxy for this. The data comes from the Danish Twin Registry, in 2002, which surveys non-identical and identical sets of twins. The data are split into age groups (25-45 and 50-70) to test for any difference in effects. The results show significant positive effects upon well-being for individuals in current cohabitation or marriage relationships relative to being single (or, more precisely, to the corresponding twin who is single). This effect is somewhat larger for males. Perhaps surprisingly, past separations appear to have statistically insignificant consequences for subjective well-being; having a current partner is what matters. By contrasting their within-twin estimates to standard Ordinary Least Squares estimates, the authors show that OLS tends to overestimate the gains for women and 
underestimate the effects for men. Nevertheless, the size of the estimated beneficial effect on wellbeing from marriage is fairly well captured by OLS. That is encouraging, in a sense, for the previous literature. While Ordinary Least Squares estimates are biased, the size of the bias, according to the twinsmethodology, appears to be no more than approximately $10 \%$. Even so, for women, unobservable characteristics that increase well-being are correlated with the chance of being married - confirming that there is a selection effect. However, although the authors do not discuss it as such, this finding is consistent with evidence of adverse selection effects among men. Here, men with lower well-being are

Money is a useful metric. Clark and Oswald (2002) suggest a way, in panel data, to put (large) dollar values on life events like marriage. By using a 17-wave German panel with 15,000 individuals, Stutzer and Frey, in a forthcoming paper, go further and analyse the two-way links between subjective well-being and marital status. After controlling for initial status and other characteristics, the authors find that the gains from marriage increase from lowest to highest across the following four marital states: separated with no partner, single, unmarried with partner, married. They provide no direct account for the selection effect but do confirm its existence. Instead, the authors demonstrate that the life satisfaction of single individuals who will later remain single is significantly lower than the life satisfaction of single individuals who will marry 4 years hence. Perhaps curiously, the effect is most pronounced for people in their twenties and for those who marry later in life, with a smaller effect at around thirty years old.

Although of a different type, the evidence of Blanchflower and Oswald (2004b), based on 14,000 American adults, is consistent with the hypothesis that marriage makes people happier. The study suffers from the limitations of pooled cross-sectional data, but it provides unusual evidence for the inclusion of a sexual activity variable in empirical analyses of happiness, and finds that married people have much more sex than other groups. The authors demonstrate that sexual activity is strongly and monotonically correlated with happiness. So more sex may be one reason why marriage raises psychological wellbeing. However, being single or divorced continues in this data set to have an adverse impact on happiness over and above the effects of reduced sexual activity.

The quality of marriage itself is likely to come increasingly under the scrutiny of researchers. For instance, Gardner and Oswald's (2005) results on British panel data reveal that, after some time, couples do recover and benefit from marital dissolution, and that on average it is those with low mental well-being scores who divorce. Finally, modern research is turning, more broadly, to the idea that adaptation may wipe out some of the psychological benefits from marriage and other life events. Lucas et al (2003) and 
Clark et al (2003) use German longitudinal data on 24,000 individuals to explore this, and do find some evidence of adaptation towards the set point or baseline. More research is needed of this important kind.

In general, the papers reviewed here are consistent with the idea that marriage improves psychological health. This is true even when comparing married couples to those who cohabit, and after controlling for selection effects. Moreover, marriage has large effects not small ones.

\section{Section III: Longevity Benefits from Marriage}

We turn now to the body.

There is remarkable evidence that marriage helps to keep human beings alive. People who are divorced or separated or widowed are at a particularly high risk of dying prematurely. Those never married face somewhat lower risks of death in any given period, but the married have easily the lowest risk of all the groups. Evidence for this is now widespread across the world. For example, in data from Bangladesh, Rahman (1993) shows that married individuals have significantly lower mortality rates than the never married or divorced, while Mete (2005) finds evidence that being married increases the chance of being alive seven years later by $5 \%$ in longitudinal data from Taiwan. Other non-longitudinal studies, that do not attempt to control for selection effects, include a 16-nation study (Hu and Goldman 1995), work on Israeli data (Manor et al 2000), and much evidence for the US (Johnson et al 2000, among others).

As ever, causality is the issue. The longitudinal studies of marriage and mortality have typically adopted the same methodology as the mental health studies. Some initial health measures are taken and used with other explanatory variables, including marital status, to predict mortality. Initial health measures are usually self-reported, which is not ideal, because the presumption is that measurement error is greater in such data. However, it has been shown that self-reported health measures are reasonably good predictors of actual mortality (Idler and Kasl 1991).

In this literature, Cox regressions are often used to estimate duration to death, or probability of death within a given period. Results are then typically described in Relative Risk ratios (so-called RRs). These describe the relative risk of each marital-status group when compared to people who are in conventional marriage. Unlike in the mental health papers, the selection effect in this literature is often estimated separately. 
An obvious difficulty is that initial health measures may not be detailed enough. If not, then there remains omitted-variable bias, and estimates of the 'causal' benefits from marriage are correspondingly contaminated by some selection. Another problem is that marital status is often measured some years before death, so full marital history is not, and often cannot be, included in the regression. Tucker et al (1996) and Cheung (2000) try to use marital history, but in doing so struggle to account for the selection effect or control for other variables.

A fascinating paper by Murray (2000) attempts to overcome this by using a complete historical data set. The paper follows a sample of subjects from an unmarried state at 18 years of age through to death. The sample are graduates from Amherst College, Massachusetts, born between 1832-79. Those who did not graduate are not followed. The sample gives date of first-marriage (only), so full marital history is unknown. The date of wife's death, however, is known. At 18, these men had their height and weight measured. Height -- although affected genetically -- depends on a person's nutrition and health. A BMI (Body Mass Index = height/mass squared) measure can be calculated. Research has found a non-linear relationship between both height and BMI with mortality (Costa 1993), although the height relationship is thought by some investigators to be spurious. In this historical Amherst study, height is divided into 5 groups, from very short [>2sd from mean] up to very tall, and BMI into 4 groups.

Regressions are estimated to explore the selection question: can initial health account for marital behaviour? First, a logit model is constructed to estimate the consequences of marriage versus lifelong bachelorhood. Other models are used to estimate the duration until first marriage. Underweight men are $4 \%$ less likely ever to marry and $12 \%$ less likely to marry in a given year $(\mathrm{p}=<0.05)$. Overweight men are $7 \%$ more likely to marry $(\mathrm{p}<0.05)$. Obesity among men led to no negative effects on their marital prospects. This may seem surprising, given modern tastes. In terms of height, only the extremes produced any significant differences in life outcomes. Very short men in the data set are much less likely to marry $(-11 \%)$. The very tall are $15 \%$ more likely to marry. Height and BMI could signal future health or productivity, or the findings may reflect tastes in physical attractiveness.

Duration-model regressions are then carried out to establish the effect of marriage on mortality, while accounting for selection effects. Using a dummy for married or not, the coefficient indicates a huge $47 \%$ reduction in within-period mortality risk for those who were married $(\mathrm{p}<0.01)$. Using a more sophisticated dummy activated in the years after marriage and not before, there is a $15 \%$ reduction in risk of death $(\mathrm{p}<0.01)$. This effect exists after controlling for initial height and BMI, occupation, and cohort. The BMI categories show an increased risk only for the obese. None of the height categories leads to 
significantly increased risk of death. Occupation indicated significant risks for physicians and attorneys compared to, for instance, teachers and ministers. The paper finds clear evidence that marriage is protective.

There is another way to think about this kind of phenomenon. Marriage can be viewed as the smallest and most intimate form of social network. Some early evidence about the influential role of social networks comes from House et al (1982) and Berkman and Syme (1979), who demonstrate that more isolated individuals have higher mortality rates. The Tecumseh Community Health Study 1967/9 samples 35-69 year olds and then assesses mortality in 1978/9. A full medical examination and medical history give initial readings on morbidity. Other variables include age, smoking, alcohol consumption, education, employment and occupation. Social network variables measure the number of intimate relationships, formal organisation involvement, and leisure activities (passive and active). These are used to predict mortality in the usual fashion, within a binary logit equation. For men, being retired and smoking are significant predictors of death, ceteris paribus. The social measures prove especially interesting. Frequency of attending voluntary associations, spectator events and classes all seem to reduce mortality $(p<0.05)$. Marriage has a large protective effect for men. For women, no statistically significant marriage benefit exists. Time spent watching television increases mortality risk $(\mathrm{p}<0.005)$, and, as in Waite and Lehrer (2003), the authors confirm that regular church attendance $(\mathrm{p}<0.025)$ is associated with a longer lifespan.

All this research is consistent with the general hypothesis that social activities and friendship networks dramatically promote longevity. Schoenbach et al (1986) attempt a similar study with different social measures, which they argue are more appropriate. The 1960 Evans County Study is used with a 6-7 year follow up. They find support for the social networks argument only in older people with fewer ties. The longevity-increasing effect is especially strong in white males. Lillard and Waite (1995) explore the effects of marital status on mortality and have a particular interest in how the duration of the status may affect mortality. If the protection effect exists, it would be useful to understand if it produces benefits that accumulate with marriage duration. To investigate this, they estimate a hazard model of mortality with a household panel from 1968-88. While having the usual controls, the authors also use status duration as an explanatory variable. The results show that married men have significantly less mortality risk while all other states are insignificantly different from each other. Married and widowed women have lower mortality risks than single or divorced/separated women. By including the duration variable the study suggests that the reduced mortality benefits cumulate over time for both sexes, while for males there is 
also an immediate benefit at the time of marriage. The authors suggest that this may be because men immediately cut back on risky actions.

As an extension of Lillard and Waite (1995), Lund et al (2004) consider the effects on mortality from a wider partnership history than current marital status. The authors use a panel of Danish men born in 1953. Their estimates suggest that marriage offers beneficial effects at any age, and, as in Lillard and Waite, that the longer the duration of a marriage the greater the gains. Lund et al also find that the duration since a divorce increases the risks of mortality, and that having higher numbers of marital dissolutions can increase mortality.

There are other persuasive papers in the literature on the health and mortality effects from marriage. Lillard and Panis (1996) make a fundamental contribution to this literature and show clear benefits from marriage, while Brockmann and Klein (2004) replicate and extend their findings. These papers are important because they simultaneously separate and measure both the selection and protection effects. Lillard and Panis use the same panel as Lillard and Waite (1995), but take a longer period, 1968-1990, and only include male individuals. First, the authors estimate a standard hazard equation, as would be commonly used in the literature, while controlling for initial health and personal characteristics. They find that the never married and the widowed have significantly higher mortality risks than the married and separated/divorced. Furthermore, the authors show that the health of never married and divorced men health deteriorates approximately $15 \%$ faster than that of married men.

However, Lillard and Panis paper's greatest innovation comes from specifying these models alongside equations that model the risks of marriage formation or dissolution. Unobserved variables may lead an individual to have better health, lower mortality risk and higher marriage formation. By estimating these equations simultaneously, it is possible to control for these effects and provide measurements of selection and protection effects. The procedure uses an instrumental variable technique and assumes that several variables concerning the individuals' childhoods and parents affect only the individuals' health but none of the other dependent variables. This assumption, however, is insensitive to the exact specification. The authors' results show that, having controlled for the selection effect, large benefits of marriage persist, with the never married and widowed men having larger risks of mortality. However, with the controls, the health effects differ slightly: now there is no significant difference between the health of the never married and married, but the benefits of marriage remain when compared to the other marital groups. Most notably, in the selection equation they find that less healthy men are more likely to marry, which is 
again suggestive of adverse selection effects into marriage. Brockmann and Klein (2004) extend Lillard and Panis (1996) by incorporating the wider effects of marital history rather than only current marital status. This allows them to see if the timing of a martial transition, the duration of a transition or the sequencing of marital transitions affects mortality. To do this they use German panel data from 1984 to 1998. Compared to married men, widowed men have a 44\% higher risk of mortality, and divorced men a $60 \%$ higher risk (after controlling for selection), while widowed women have 36\% and single women $50 \%$ greater risks. These are enormous effects from relationships.

Hibbard and Pope (1993) focus on finding out how the quality of a marriage affects mortality and morbidity. Marital quality is measured with some responses to questions designed to provide index values on of marital satisfaction, equality in decision-making and marriage companionship. While controlling for baseline health and other personal factors, the authors analyse mortality over a fifteen-year follow up. They find that marriage quality affects mortality risk for females but not males. Ben-Shlomo et al (1993) use a sample of middle-aged males from the UK civil service, over an 18-year period. In 1967-69, their sample is of approximately 18,000 men, aged between 40 and 64 years old. After an 18-year follow up period, those who had died (3433) are categorised by cause of death. The figures per 1000 persons, adjusted for age, show that married individuals have a 13.9 mortality rate, while the widowed, single and separated have rates of 20.6, 16.9 and 21.0 respectively. The main difference between married and single men seems to come from differences in rates of cardiovascular disease and lung cancer. This may tell us something about how a protective effect operates.

Somewhat different conclusions are drawn by Ebrahim et al (1995). Only the single have excess mortality risk, and not the divorced or widowed. The research monitors middle-aged British men from 1978/80 to 1983/85. Explanatory variables in the statistical work include employment and occupation status, medical history with medical assessments including activity measures, and smoking/drinking consumption.

A 10-year panel of British households is used by Gardner and Oswald (2004) to compare the mortality effects of marriage relative to income. They also find large benefits of marriage - enough to offset the risk of smoking for men, and enough to offset approximately half the smoking risk for women. A novel aspect in this study is the inclusion of mental stress measures in the controls for health. In principle, this not only provides a better control for the estimation, but also allows the authors to test whether the beneficial effect from marriage arises through reductions in stress. The data suggest it does not. After controlling for other factors, the coefficient on marriage in the authors' mortality equation is unaffected 
by the inclusion of a mental health measure (the so-called GHQ score). This suggests that there are other important, and as yet incompletely understood, channels at work behind the correlation between marriage and mortality.

In Tucker (1996), marital history is monitored up to the middle of life. Cox regressions are used to predict mortality. Marital turbulence matters. Adjusting for self-reported health, inconsistently married men have a $40 \%$ greater risk of dying, the divorced a $250 \%$ greater risk, and the single no significant risk above the consistently married males. When social-ties measures are allowed for, the risk for single males is eliminated, and the risk for divorced males is somewhat reduced. For females, whether or not social ties are included in the equation, the divorced have a dramatically higher risk of mortality than the married. Cheung (2000) explores a longitudinal data set on British women, and has a time-varying independent variable to allow for marital status durations. An initial assessment in 1984-5 in which the women were 35 and older was followed up twelve years later. Self-reported health, height, education and smoking /drinking habits are included, but social networks and financial status are not. The results find excess mortality in the unmarried but not the divorced or widowed. The single face an odds ratio as high as 1.45 $(\mathrm{p}<0.05)$.

A non-longitudinal approach is employed in Rogers (1995). With a case control method, which is more common in epidemiology, interesting conclusions are drawn about the causes of death. Contrary to the idea that selection effects explain the correlation between marriage and wellbeing, the biggest observed gaps are in social causes of death (suicide, accidents, and cirrhosis of the liver). The National Mortality Followback Survey sampled 18733 deaths in 1986. Socio-economic status and cause of death are measured. Matched to this is another sample of individuals who lived through 1986, to give a total sample of 36142 individuals. Controlling for socio-economic status and income, marriage offers a 20\% risk advantage to women, and much more men. Unmarried males are 2-3 times more likely to die than married men. The protective effect is especially strong against 'social' causes of death (classified here as accidents, suicide, homicide or cirrhosis).

Summarizing this evidence, marriage has enormous effects on people’s longevity.

\section{$\underline{\text { Section IV: Health Benefits from Marriage }}$}

Since a much-cited study by Verbrugge (1979), many investigators have tried to work out whether marriage makes people generally healthier. 
Joung et al (1998) takes longitudinal data from the Dutch GLOBE Project. Here the aim is a little different. The data are used to test whether health measures can predict marital status i.e. if there is a health-driven selection effect. The GLOBE study is longitudinal and follows individuals aged between 15-74; the subjects come from around Eindhoven; the survey response rate was 70\%. Here all those living in Eindhoven are used (10811). Between 1991 and 1995, marital status changes, deaths and migrations are all monitored. Perceived general health, subjective health complaints and chronic conditions are used as health measures. Age, sex, education level, religion and employment status are controlled for. Regressions are used to establish relative risks (RRs) of the various changes in marital status. The transition from marriage to divorce reveals evidence that health determines the probability of marriage.

Waldron et al (1996) demonstrate that jobs provide valuable social networks outside marriage, and that these improve mental and physical health. The unemployed lose this channel of emotional support, (Waldron and Jacobs 1988,1989). The authors use the National Longitudinal Surveys of Labour Market Experience, covering US women in 1968,1978,1983,1988. The cohort start aged 14-24yrs, and end at 3444yrs. A health scale is constructed from 11 questions on physical difficulties and 6 questions on more general difficulties, e.g. tiredness. Working hours are measured. Other controls include age, gender and parental status. No measures for income or social networks are available. For 1978 and 1983-88, OLS is used to predict health status - to test for protective effects from being married. Initial marital status seemed to be a good predictor of later health. This varies, however, as interaction terms are included. Part-time and full-time married women appear to gain no protection; only non-working married women do. No other significant differences in the protective effect is found. Next, selection effects are tested by predicting marital status over the 2 periods. In the $1^{\text {st }}$ period, initial health is a strong indicator, but not in the $2^{\text {nd }}$. Again the effect varies by employment. No selection effect is discovered for full-timers.

The possibility of adverse selection into marriage is supported by studies based on a British cohort (Cheung 1998, Cheung and Sloggett 1998). The National Child Development study follows children born in a particular week of 1958 with follow-ups at 7,11,16,23, and 33. Variables included are social class and housing tenure, education, unemployment record, alcohol / smoking consumption, health measures height, weight, self-reported measures and limiting illnesses. Also included is a variable aimed at estimating temperament. Cheung (1998) uses those married or divorced at 33 years of age to try to understand the probability of divorce. Logit models for females indicate that council renters and heavy drinkers are more likely to divorce. An adverse selection effect in health is found. Those with poor selfrated health are less likely to divorce, with an odds ratio of $0.57 \mathrm{p}<0.1$. For men, heavy smokers are less 
likely to divorce (OR 0.54, $\mathrm{p}<0.05$ ). Replicating this study, but using the selection from single to married, Cheung and Sloggett (1998) find only positive selection effects between the 23-33yrs assessments. Between 16-23 the results are less clear. This work is consistent with the hypothesis that that there are adverse selection effects from marriage to divorce, but not from single to married.

One branch of the literature looks specifically at the health gains of marriage for the elderly (Goldman et al (1995), Pienta et al (2000)). Pienta et al confirm the considerable benefits of marriage across a wide sample. Goldman et al, using longitudinal data over a 6-year follow up period, struggle to find statistically significant results. Only widowers show increased risk.

An important study into the effects of marriage on the incidence of Alzheimer's disease is Helmer et al (1999). Using a French longitudinal data set that includes variables for socio-demographics, social support, living conditions, health and depression measures, and medical history, the authors find significantly higher risk of Alzheimer’s among the never married.

Wickrama et al (1997) present a longitudinal study analysing the links between the marriage quality and health benefits. A marital quality index is constructed from questioning a set of 364 married couples with questions about happiness, satisfaction, thoughts of divorce and troubled periods. While controlling for personal factors, including the level of distress and risky behaviours, the authors link changes in marital quality with changes in self-reported health over a three-year period. Using an unusual latent growth curve analysis they are able to show that, for both sexes, increases in marriage quality bring about large perceived benefits in health. Most interestingly, the mechanism by which this is caused is identified as marriage quality reducing distress, which in turn reduces risky behaviours, which brings health benefits.

In similar work, Prigerson et al (1999) link marital harmony with measures of health for a set of married women over a three year follow up. The health measures used are more robust -- including not only selfreports of specific conditions but health service use. Results show that marital harmony is associated with much better sleep, less depression and fewer visits to the doctor. Williams and Umberson (2004) analyse the effects of marital history and the timing of marital transitions on health. They use a short US panel. Remarriages confer benefits that weaken with age. The latest work continues to suggest that a person's whole marital history matters (Hughes and Waite, 2005). Much more research is needed here.

Health, also, is improved by marriage - especially a good one. 
Section V: Investigations into the Channels Providing the Benefits from Marriage

If we accept from all this statistical evidence that human beings gain some kind of protective effect from marriage, how are those benefits actually transmitted? The answer is not yet known.

Married couples may gain financially. Marriage may bring increased emotional and instrumental support. Marriage may change lifestyles because of some kind of guardian effect, where healthy activities are increased and risky behaviours reduced. We have already seen some possible evidence for such channels; but again, selection effects may distort these results. Higher socio-economic status and financial advantages for the married have been shown (Brown 2000, Ross 1995, Rindfuss and Vanden Heuvel 1990). Ross (1995) establishes that the married have higher levels of emotional support. Evidence of married individuals drinking and smoking less has been found, perhaps suggestive of a guardian effect (Horwitz et al 1996, Ben-Shlomo 1993). Rogers (1995) prove that married people are less likely to die from accidents, suicide and cirrhosis of the liver.

We should mention three papers that explore these explanations. All use cross sectional data, so have limitations, but the patterns are of interest. The papers are as follows. Joung et al (1997) have data that come from the GLOBE project in Eindhoven and its surroundings. The response rate was 70\%. Wyke and Ford (1992) review the explanations, and test them. A sample of 55-year old women from around Glasgow is used. Hahn (1993) examines 14,000 households in the US. All three papers point to financial factors as being important.

Umberson (1987, 1992) investigates the guardian effect further. A US sample of 1826 married or divorced/separated individuals in the mid 1970s is used to investigate this channel. Six indices measuring orderliness of lifestyle, risk taking behaviour, drinking problems, drinking and driving, marijuana use and substance abuse related to stress are all constructed. Parental status (kids at home, kids not at home, no kids), age, education, gender and race are also all controlled for statistically. The divorced are found to be more likely to have adverse (higher) scores in the indices -- showing a lack of healthy behaviour and high risk-taking behaviours.

By looking at changes in drinking patterns, Power (1999) attempts to factor out the selection effect. The well-known British birth cohort of 3-9 March 1958 had data collected about them at ages 7,11,16,23 and 33. At age 33, 69\% of the sample (11045) remain. Getting married per se seems to reduce male drinking; but parenting is a stronger force in reducing married women's drinking. The recently divorced change 
their drinking behaviour after remarriage. They show a large rise in drinking but the continuously married and not recently divorced show small declines in drinking. This paper demonstrates the absence of strong selection effects in terms of alcohol consumption, but strong effects for those experiencing changes in marital status. Becoming married makes alcohol consumption fall, and recent divorce causes it to rise. This would seem to confirm the existence of at least some guardian effect. Wickrama et al (1995) find that positive interaction within a marriage increases health by reducing the propensity to live an unhealthy lifestyle. The study uses a 4-wave panel of 320 men who had been married over 14 years with at least 2 children. Burke et al (2004) uncover mixed evidence of the effect of living with a partner. The authors use a panel that follows a set of nine-year old, Australian children from 1985. The study tracks the consequences of living with a partner for health, but no distinction is made between marital and nonmarital cohabitation. The individuals in 2000 are only 25 years old, so not only are the measured effects possibly short-term but they are also likely to capture young partnerships that may not be entirely representative of the population. Despite these shortcomings, the results are interesting and show that, for women especially, there is a notable increase in body mass index associated with living with a partner, which has been noted before (e.g. Sobal et al (2003)). In contrast, men have a reduced fat and energy intake in their diet, perhaps as an effect of the partner changing their eating habits.

The papers covered in this section do not offer overwhelming evidence for any of the explanations suggested about why marriage is good for people. Power et al (1999) is the only study that can reject the selection explanation, and Power et al's study is limited by possible misspecification.

In our judgment, a more promising way to think about all these phenomena is to look at laboratory work. Cohen et al $(1997,2003)$ show that, in randomised trials, people who have stronger social ties are better able to withstand cold viruses. In each of these two studies, some hundreds of volunteers are exposed to nasal drops containing 1 of 2 rhinoviruses, and monitored to see who develops the common cold. The subjects are interviewed about their social networks and relationships, and studied in actual social settings. Increased sociability is found to be associated in a monotonically decreasing way with the probability of developing a cold. The statistical association remains after allowance for many controls, including baseline immunity, demographic factors, smoking, alcohol consumption, education, body mass index, and diet. This research is important.

How such protective channels work remains an open question. The results in Gardner and Oswald (2004) appear to indicate that it is not merely that marriage keeps people alive by reducing stress levels. In 
mortality equations on longitudinal British data, the authors find that their large negative coefficient on marriage is unaffected by the inclusion of a mental stress variable.

\section{$\underline{\text { Conclusions }}$}

Married people live longer and are healthier. What is less clear is whether this pattern in the data tells us something reliable about what marriage does to health.

This paper reviews the modern longitudinal evidence. By studying people over time, it is possible to draw more persuasive judgements than by looking at cross-sectional evidence. The same person can be followed through the years, and that makes it feasible to factor out influences that are specific to the person. Longitudinal data also make it possible for people's early health to be held constant within an equation that explains their health and mortality later in life. It is important to be clear, nevertheless, that longitudinal data do not solve all problems in this or other fields. First, as the philosopher David Hume pointed out, just because something moves first does not mean that it causes what goes second, no matter how reliable the correlation. Hume's example was the crowing of the cock followed by the invariable rising of the sun. Second, human beings are not, of course, randomly assigned to marriage. They choose it. Because of that, there are likely always to be difficulties about how to interpret the deep links between marriage and wellbeing.

Nevertheless, our reading of the longitudinal evidence, after looking across studies in a variety of literatures, suggests that:

- Marriage makes people far less likely to suffer psychological illness

- Marriage makes people live much longer

- Marriage makes people healthier and happier

- Both men and women benefit, though some investigators have found that men gain more

- These gains are not merely because married people engage in less risky activities

- Marriage quality and prior beliefs can influence the size of the gains.

In the terminology of this research field, there is a genuine protection effect from marriage. The pattern in the data is not a cross-section illusion. Moreover, it is large: for males the longevity effect of marriage may even offset the consequences of smoking. What, in a deep sense, are the processes at work? It does 
not seem merely to be that having a wife or husband lowers a person's stress and that this makes the person physically healthier.

Marriage is arguably the most fundamental of all social ties. Hence the Cohen laboratory studies (1997, 2003), which show that human beings with good friendship networks can repel the simple common cold, are particularly suggestive. Our empirical instinct is that intimate friendships provide a kind of deep protection from attacks such as infections and medical disorders. Perhaps, figuratively speaking, marriage is like having a reserve army of volunteers, rather than simply a large army of regulars. How marriage works its magic remains mysterious. If an answer can be found, it may unlock the puzzle of exactly how the mind and body are intertwined. 


\section{References}

Barrett, A.E. (2000), “Marital Transitions and Mental Health”, Journal of Health and Social Behaviour, 45, 451-464.

Becker, G.S. (1981), A Treatise on the Family, Chicago: University of Chicago Press.

Ben-Shlomo, Y., G.D. Smith and M. Shipley et al (1993), "Magnitude and Causes of Mortality Differences Between Married and Unmarried Men”, Journal of Epidemiology and Community Health, 47, 200-205.

Berkman, L.F. (1988), “The Changing and Heterogeneous Nature of Aging and Longevity: A Social and Biomedical Perspective”, Annual Reviews in Gerontology and Geriatrics, 8, 37-68.

Berkman, L.F. and S.L. Syme (1979), "Social Networks, Host Resistance and Mortality: A Nine Year Follow-Up Study of Alameda County Residents”, American Journal of Epidemiology, 109, 186-204.

Blanchflower D.G. and A.J. Oswald (2004a), “Well-Being Over Time in Britain and the USA”, Journal of Public Economics, 88, 1359-1386.

Blanchflower D.G. and A.J. Oswald (2004b), "Money, Sex and Happiness: An Empirical Study", Scandinavian Journal of Economics, 106, 393-415.

Brockman H. and T. Klein (2004), "Love and Death in Germany: The Marital Biography and Its Effect on Mortality”, Journal of Marriage and the Family, 66, 567-581.

Brown, S.L. (2000), “The Effect of Union Type on Psychological Wellbeing: Depression Cohabitants Versus Marrieds”, Journal of Health and Social Behaviour, 41, 241-255.

Brown, S.L. and A. Booth (1996), "Cohabitation Versus Marriage: A Comparison of Relationship Quality”, Journal of Marriage and the Family, 58, 668-678.

Bumpass, L.L. and J.A. Sweet (1989), “National Estimates of Cohabitation”, Demography, 26, 615-25.

Burke V., L.J. Beilin, and D. Dunbar et al. (2004), "Changes in Health Related Behaviours and Cardiovascular Risk Factors in Young Adults: Associations with Living with a Partner”, Preventive Medicine, 39, 722-730.

Burman, B. and G. Margolin (1992), “Analysis of the Association Between Marital Relationships and Health Problems: An Interactional Perspective”, Psychological Bulletin, 112, 39-63.

Cheung, Y.B. (1998), "Can Marital Selection Explain the Differences in Health Between Married and Divorced People? From a Longitudinal Study of a British Birth Cohort”, Public Health, 112, 113-117.

Cheung, Y.B. (2000), "Marital Status and Mortality in British Women: A Longitudinal Study", International Journal of Epidemiology, 29, 93-99.

Cheung, Y.B. and A. Sloggett (1998), "Health and Adverse Selection into Marriage: Evidence from a Study of the 1958 British Birth Cohort Study”, Public Health, 112, 309-311. 
Chun, H. and I. Lee (2001), "Why Do Married Men Earn More: Productivity or Marriage Selection?”, Economic Inquiry, 39, 7-19.

Clark, A.E., E. Diener, Y. Georgellis, and R.E. Lucas (2003), "Lags and Leads in Life Satisfaction: A Test of the Baseline Hypothesis”, working paper, DELTA, Paris.

Clark, A.E. and A.J. Oswald (2002), “A Simple Statistical Method for Measuring How Life Events affect Happiness”, International Journal of Epidemiology, 31, 1139-1144.

Cohen, S. (2004), “Social Relationships and Health”, American Psychologist, 59, 676-684.

Cohen, S., W.J. Doyle, D.P. Skoner, B.S. Rabin, and J.M. Gwaltney (1997), "Social Ties and Susceptibility to the Common Cold”, Journal of the American Medical Association, 277, 1940-1944.

Cohen, S., W.J. Doyle, R. Turner, C.M. Alper (2003), and D.P. Skoner “Sociability and Susceptibility to the Common Cold”, Journal of the American Medical Association, 14, 389-395.

Collins, R. and S. Coltrane (1992), Sociology of Marriage and the Family: Gender, Love and Property $3^{\text {rd }}$ ed. Nelson Hall, Chicago

Coombs, R. (1991), “Marital Status and Personal Wellbeing: A Literature Review”, Family Relations, 40, 97-102.

Costa, D.L. (1993) "Height, Weight, Wartime Stress and Older Age Mortality: Evidence from Union Army Records”, Explorations in Economic History, 30, 424-49.

Daniel, K. (1995) “The Marriage Premium” Ch.7 from The New Economics of Human Behaviour (eds) M. Tommasi and K. Ierulli, Cambridge University Press.

Di Tella, R., MacCulloch, R., and Oswald, A. J. (2003), “The Macroeconomics of Happiness”, Review of Economics and Statistics, 85, 809-827.

Ebrahim, S., G. Wannamethee and A. Mccallum et al. (1995), "Marital Status, Change in Marital Status and Mortality in Middle Aged British Men”, American Journal of Epidemiology, 142, 834-842.

Gardner J. and A. Oswald (2004), “How is Mortality Affected by Money, Marriage and Stress?”, Journal of Health Economics, 23, 1181-1207.

Gardner J. and A. Oswald (2005), “Do Divorcing Couples Become Happier by Splitting Up?”, working paper, Warwick University.

Glenn, N.D. and C.N. Weaver (1988), "The Changing Relationship of Marital Status to Reported Happiness”, Journal of Marriage and the Family, 50, 317-324.

Goldman, N., S. Korenman and R. Weinstein (1995), "Marital Status and Health Among the Elderly”, Social Science and Medicine, 40, 1717-1730.

Gove, W.R., M. Hughes and C.B. Style (1983), "Does Marriage Have Positive Effects on the Psychological Well-being of the Individual?”, Journal of Health and Social Behaviour, 24, 122-131. 
Hahn, B.A. (1993), "Marital Status and Women's Health: The Effect of Marital Economic Marital Acquisitions", Journal of Marriage and the Family, 55, 495-504.

Helmer, C., D. Damon and L. Letenneur et al. (1999), “Marital Status and Risk of Alzheimer’s Disease”, Neurology, 53, 1953-1958.

Hibbard J.H. and C. R. Pope (1993), “The Quality of Social Roles as Predictors of Morbidity and Mortality”, Social Science and Medicine, 36, 217-225.

Horwitz, A.V., H.R. White and S. HowellWhite (1996), "Becoming Married and Mental Health: A Longitudinal Study of a Cohort of Young Adults”, Journal of Marriage and the Family, 58, 895-907.

Horwitz, A.V. and H.R. White (1998), "The Relationship of Cohabitation and Mental Health: A Study of a Young Adult Cohort”, Journal of Marriage and the Family, 60, 505-14.

House, J.S., C. Robbins and H. Metzner (1982), "The Association of Social Relationships and Activities with Mortality: Prospective Evidence from the Tecumseh Community Health Study”, American Journal of Epidemiology, 116, 567-567.

House, J.S., K.R. Landis and D. Umberson (1988), “Social Relationships and Health”, Science, 241, 540545.

Hu, Y. and N. Goldman (1995), "Mortality Differentials by Marital Status: An International Comparison”, Demography, 32, 485-507.

Hughes, M.E. and L.J. Waite (2005) "Marital Biography and Health at Midlife”, working paper, Department of Sociology, Duke University.

Idler, E.L. and S. Kasl (1991) "Health Perceptions and Survival: Do Global Evaluations of Health Status Really Predict Mortality?”, Journal of Gerontology, 46, S55-65.

Johnson, D.R. and J. Wu (2002), “An Empirical Test of Crisis, Social Selection, and Role Explanations of the Relationships Between Marital Disruption and Psychological Distress: A Pooled Time Series Analysis of Four-Wave Panel Data”, Journal of Marriage and the Family, 64, 211-224.

Johnson, N.J., E. Backlund and PD Sorlie et al (2000), "Marital Status and Mortality: The National Longitudinal Mortality Study”, Annals of Epidemiology, 10, 224-238.

Joung, I.M.A., K. Stronks and H.D. Vandemheen et al. (1997), "The Contribution of Intermediary Factors to Marital Status Differences in Self Reported Health”, Journal of Marriage and the Family, 59, 476-490.

Joung, I.M.A., H.D. Vandemheen and K. Stronks et al. (1998), "A Longitudinal Study of Health Selection in Marital Transitions”, Social Science and Medicine, 46, 425-35.

Kessler, R.C. and M. Essex (1982), "Marital Status and Depression: The Importance of Coping Resources”, Social Forces, 61, 484-507.

Kiecolt-Glaser J.K. and T.L. Newton (2001), "Marriage and Health: His and Hers”, Psychological Bulletin, 127, 472-503. 
Kim H.K. and P.C. McKenry (2002), "The Relationship Between Marriage and Psychological WellBeing: A Longitudinal Analysis”, Journal of Family Issues, 23, 885-911.

Kohler H-P., J.R. Behrman and A. Skytthe (2004), "Partner + Children = Happiness? An Assessment of the Effect of Fertility and Partnerships on Subjective Well Being”, working paper, University of Pennsylvania.

Lee, G.R., K. Seccombe and C.L. Sheehan (1991), "Marital Status and Personal Happiness: An Analysis of Trend Data”, Journal of Marriage and the Family, 53, 839-844.

Lillard L.A. and Waite L.J. (1995), “'Til Death Do Us Part: Marital Disruption and Mortality”, American Journal of Sociology, 100, 1131-1156.

Lillard, L.A. and C.W.A. Panis (1996), “Marital Status and Mortality: The Role of Health”, Demography, 33, 313-327.

Loh, E.S. (1996), “Productivity Differences and the Marriage Wage Premium for White Males”, Journal of Human Resources, 31, 566-89.

Lucas, R.E., A.E. Clark, Y. Georgellis and E. Diener (2003), "Re-examining the Set Point Model of Happiness: Reactions to Changes in Marital Status”, Journal of Personality and Social Psychology, 84, 527-539.

Lund R., B.E. Holstein and M.Osler (2004), "Marital History From Age 15 to 40 Years and Subsequent 10-Year Mortality: A Longitudinal Study of Danish Males Born in 1953”, International Journal of Epidemiology, 33, 389-397.

Manor, O., Z. Eisenbach and A. Israeli et al. (2000), "Mortality Differentials Among Women: The Israel Longitudinal Mortality Study”, Social Science and Medicine, 51, 1175-1188.

Marks N.F. and Lambert J.D. (1998), “Marital Status Continuity and Change Among Young and Midlife Adults: Longitudinal Effects on Psychological Well-Being”, Journal of Family Issues,19, 652-686.

Masterkaasa, A. (1992), "Marriage and Psychological Well-being: Some Evidence on Selection Into Marriage”, Journal of Marriage and the Family, 54, 901-911.

Mete, C. (2005), "Predictors of Elderly Mortality: Health Status, Socioeconomic Characteristics and Social Determinants of Health”, Health Economics, 14, 135-148

McLanahan, S. and J. Adams (1987), "Parenthood and Psychological Wellbeing”, Annual Review of Sociology, 13, 237-257.

Murray, J.E. (2000), “Marital Protection and Marital Selection: Evidence From a Historical-Prospective Sample of American Men”, Demography, 37, 511-521.

Pienta, A.M., M.D. Hayward and K.R. Jenkins (2000), "Health Consequences of Marriage for the Retirement Years”, Journal of Family Issues, 21, 559-586.

Power, C., B. Rodgers and S. Hope (1999), "Heavy Alcohol Consumption and Marital Status: Disentangling the Relationship in a National Study of Young Adults”, Addiction, 94, 1477-1487. 
Prigerson H.G., P.K. Maciejewski and R.A. Rosenheck (1999), “The Effects of Marital Dissolution and Marital Quality on Health and Health Service Use Among Women”, Medical Care, 37, 858-873.

Rahman, O. (1993), “Excess Mortality for the Unmarried in Rural Bangladesh”, International Journal of Epidemiology, 22, 445-456.

Reed, R.W. and K. Harford (1989), “The Marriage Premium and Compensating Wage Differentials”, Journal of Population Economics, 2, 237-65.

Ren X.S. (1997), “Marital Status and Quality Relationships: The Impact of Health Perception”, Social Science and Medicine, 44, 241-249.

Rindfuss, R.R. and A. VandenHeuvel (1990), "Cohabitation: A Precursor to Marriage or an Alternative to Being Single?”, Population and Development Review, 16, 703-726.

Rogers, R.G. (1995), “Marriage, Sex and Mortality”, Journal of Marriage and the Family, 57, 515-526.

Ross, C.E., J. Mirowsky and K. Goldsteen (1990), “The Impact of the Family on Health: The Decade in Review”, Journal of Marriage and The Family, 52, 1059-1078.

Ross, C.E. (1995), "Reconceptualizing Marital Status as a Continuum of Social Attachment”, Journal of Marriage and the Family, 57, 129-140.

Schoenbach, V.J., B.H. Kaplan and L. Fredman et al (1986), "Social Ties and Mortality in Evans County, Georgia”, American Journal of Epidemiology, 123, 577-591.

Shumaker, S.A. and D.R. Hill (1991), “Gender Differences in Social Support and Physical Health”, Health Psychology, 10, 102-11.

Simon R.W. (2002), "Revisiting the Relationships among Gender, Marital Status and Mental Health”, American Journal of Sociology, 107, 1065-1096.

Simon, R.W. and K. Marcussen (1999), “Marital Transitions, Marital Beliefs and Mental Health”, Journal of Health and Social Behaviour, 40, 111-125.

Smock, P.J., W.D. Manning and S. Gupta (1999), “The Effect of Marriage and Divorce on Women’s Economic Wellbeing”, American Sociological Review, 64, 794-812.

Sobal, J., B. Rauschenbach and E.A. Frongillo (2003), "Marital Status Changes and Body Weight Changes: A US Longitudinal Analysis”, Social Science and Medicine, 56, 1543-1555.

Stack, S. and J.R. Eshleman (1998), “Marital Status and Happiness: A 17 Nation Study”, Journal of Marriage and the Family, 60, 527-536.

Stutzer A. and Frey B.S. (forthcoming), "Does Marriage Make People Happy or Do Happy People Get Married?”, Journal of Socio-Economics.

Tucker, J.S., D.L. Wingard and H.S. Friedman et al. (1996), "Marital History at Midlife as a Predictor of Longevity: Alternative Explanations to the Protective Effect of Marriage”, Health Psychology, 15, 94101. 
Umberson, D. (1987), "Family Status and Health Behaviours: Social Control as a Dimension of Social Integration”, Journal of Health and Social Behaviour, 28, 306-19.

Umberson, D. (1992), “Gender, Marital Status and the Social Control of Health Behaviour”, Social Science and Medicine, 34, 907-917.

U.S. Bureau of the Census (1999) "Unmarried couple Households by Presence of Children: 1960 to Present, AD-2” Washington D.C.

Verbrugge, L.M. (1979), “Marital Status and Health”, Journal of Marriage and the Family, 41, 267-285.

Waite, L.J. (1995), “Does Marriage Matter?”, Demography, 32, 485-507.

Waite L.J. and Lehrer E.L. (2003), “The Benefits From Marriage and Religion in the United States: A Comparative Analysis”, Population and Development Review, 29, 255-275.

Waldron, I. and J.A. Jacobs (1988), "Effects of Labour Force Participation on Women's Health: New Evidence from a Longitudinal Study”, Journal of Occupational Medicine, 30, 977-983.

Waldron, I. and J.A. Jacobs (1989,) “Effects of Multiple Roles on Women's Health: Evidence from a National Longitudinal Study”, Women Health, 115, 3-19.

Waldron, I., M.E. Hughes and T.L. Brooks (1996), "Marriage Protection and Marriage Selection Prospective Evidence for Reciprocal Effects of Marital Status on Health”, Social Science and Medicine, 43, 113-123.

Wickrama K., R.D. Conger and F.O. Lorenz (1995), “Work, Marriage, Lifestyle and Changes in Men’s Physical Health”, Journal of Behavioral Medicine, 18, 97-111.

Wickrama K.A.S., R.D. Conger and F.O. Lorenz et al (1997), "Marital Quality and Physical Illness: A Latent Growth Curve Analysis”, Journal of Marriage and the Family, 59, 143-155.

Williams K. and Umberson D. (2004), "Marital Status Stability, Marital Transitions and Health: A Life Course Perspective”, Journal of Health and Social Behavior, 45, 81-98.

Wyke, S. and G. Ford (1992), "Competing Explanations for Associations Between Marital Status and Health”, Social Science and Medicine, 34, 523-532. 